\title{
31
}

\section{RANDOM VIBRATIONS OF STRUCTURES UNDER PROPAGATING EXCITATIONS}

\section{by Zbigniew ZEMBATY}

Technical University of Opole, ul.Mikołajczyka 5, 45-233 Opole, POLAND

\section{Introduction}

The problem of vibrations of structures under incoherent or, in particular, propagating excitations is important for large, extended civil engineering structures like bridges, lifelines, dams, offshore structures or for aircraft structures. In seismic engineering spatial ground motion models have been studied for more than a decade but credible, stochastic characteristics are available only since SMART-1 accelerograph array is in operation at Lotung in Taiwan.

Based on the spatial ground motion models the structural response can be analyzed in form of spatial response spectra [1-4] or for various specific types of structures, e.g. [5-11].

In present paper the problem is analyzed again and illustrated by an example of random vibrations of a bridge structure under kinematic wave excitations.

\section{Equations of motion and mean square response}

Consider equation of motion of discrete systems under kinematic excitations:

$$
[\mathrm{M}]\left\{\ddot{\mathrm{q}}^{\mathrm{t}}\right\}+[\mathrm{C}]\left\{\dot{\mathrm{q}}^{\mathrm{t}}\right\}+[\mathrm{K}]\left\{\left\{\mathrm{q}^{\mathrm{t}}\right\}=\{0\}\right.
$$

where $[\mathrm{M}],[\mathrm{C}],[\mathrm{K}]$ are mass, damping and stiffness matrices, vector $\left\{q^{\mathrm{t}}\right\}=\left\{\mathbf{q}_{1}^{\mathrm{t}}\right.$, $\left.q_{2}^{t}, \ldots, q_{n}^{t}\right\}^{T}$ represents total displacements (fixed reference) and symbol ${ }^{T}$ stands for transposition. These $n$ degrees of freedom can be divided onto $n_{s}$ structural degrees and $n_{g}$ degrees associated with ground motion $\left(n=n_{s}+n_{g}\right)$. Then eq. 1 takes form

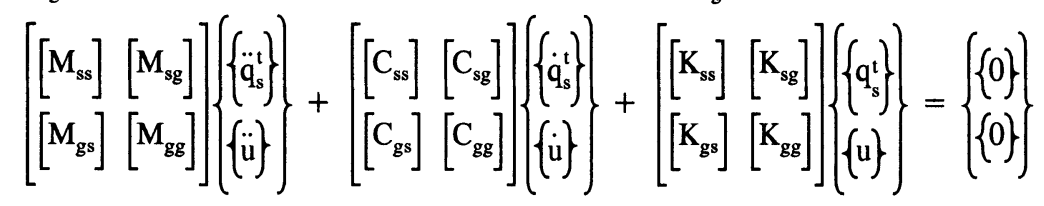


where vector $\{u\}=\left\{u_{1}, u_{2}, \ldots, u_{n_{g}}\right\}^{T}$ describes the free field motion (excitations). The total response $\left\{q^{t}\right\}$ can be separated onto dynamic $\{q\}$ and pseudo-static $\left\{q^{p}\right\}$.

$$
\left\{q^{t}\right\}=\left\{\begin{array}{l}
\left\{q^{p}\right\} \\
\{u\}
\end{array}\right\}+\left\{\begin{array}{l}
\{q\} \\
\{0\}
\end{array}\right\} .
$$

Substituting eq. 3 into the equation of motion (2) and dropping dynamic terms one obtains the pseudo-static motion

$$
\left\{\mathrm{q}^{\mathrm{p}}\right\}=-\left[\mathrm{K}_{\mathrm{ss}}\right]^{-1}\left[\mathrm{~K}_{\mathrm{sg}}\right]\{\mathrm{u}\} .
$$

Substituting again eqs. 4 and 3 into 2 and assuming either the stiffness proportional damping or that the damping contribution to effective force is negligible leads to:

$$
\left[\mathrm{M}_{\mathrm{ss}}\right]\{\ddot{\mathrm{q}}\}+\left[\mathrm{C}_{\mathrm{ss}}\right]\{\dot{\mathrm{q}}\}+\left[\mathrm{K}_{\mathrm{ss}}\right]\{\mathrm{q}\}=\left(\left[\mathrm{M}_{\mathrm{ss}}\right]\left[\mathrm{K}_{\mathrm{ss}}\right]^{-1}\left[\mathrm{~K}_{\mathrm{sg}}\right]-\left[\mathrm{M}_{\mathrm{sg}}\right]\right)\{\ddot{\mathrm{u}}\} \text {. }
$$

For all the analyzed degrees of freedom vector of the associated generalized elastic forces is equal to

$$
\{\mathrm{f}\}=[\mathrm{K}]\left\{\mathrm{q}^{\mathrm{t}}\right\} \text {. }
$$

Separating the forces onto structural $\left\{\mathrm{f}_{\mathrm{s}}\right\}$ and support $\left\{\mathrm{f}_{\mathrm{g}}\right\}$

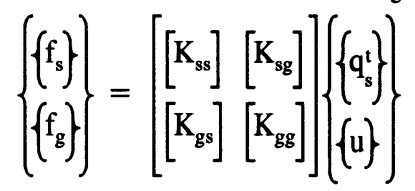

where $\left\{f_{s}\right\}=\left\{f_{1}, \ldots, f_{n_{s}}\right\}^{T}$ and $\left\{f_{g}\right\}=\left\{f_{1}, \ldots, f_{n_{f g}}\right\}^{T}$. From eq. 11

$$
\begin{aligned}
& \left\{\mathrm{f}_{\mathrm{s}}\right\}=\left[\mathrm{K}_{\mathrm{ss}}\right]\left\{\mathrm{q}_{\mathrm{s}}^{\mathrm{t}}\right\}+\left[\mathrm{K}_{\mathrm{sg}}\right]\{\mathrm{u}\}, \\
& \left\{\mathrm{f}_{\mathrm{g}}\right\}=\left[\mathrm{K}_{\mathrm{gs}}\right]\left\{\mathrm{q}_{\mathrm{s}}^{\mathrm{t}}\right\}+\left[\mathrm{K}_{\mathrm{gg}}\right]\{\mathrm{u}\}
\end{aligned}
$$

Substituting from eq. $3\left\{\mathrm{q}_{\mathrm{s}}^{\mathrm{q}}\right\}=\left\{\mathrm{q}^{\mathrm{p}}\right\}+\{\mathrm{q}\}$ and applying eq.4 one obtains

$$
\begin{gathered}
\left\{\mathrm{f}_{\mathrm{s}}\right\}=\left[\mathrm{K}_{\mathrm{ss}}\right]\{\mathrm{q}\} \\
\left\{\mathrm{f}_{\mathrm{g}}\right\}=\left[\mathrm{K}_{\mathrm{gs}}\right]\{\mathrm{q}\}+\left(\left[\mathrm{K}_{\mathrm{gg}}\right]-\left[\mathrm{K}_{\mathrm{gs}}\right]\left[\mathrm{K}_{\mathrm{ss}}\right]^{-1}\left[\mathrm{~K}_{\mathrm{sg}}\right]\right\}\{\mathrm{u}\} .
\end{gathered}
$$

It is interesting to note from eq.10 that the forces associated with structural degrees of freedom depend only on dynamic displacements of the structure which, in turn, depend on "averaged" excitations of the structure. On the other hand the forces associated with support degrees of freedom (eq.11) depend on two terms: dynamic and pseudo-static. The calculated elastic forces may be applied in calculations of any 
desired inner forces (shear, axial or moments). In practice however the forces in the structure are are calculated using the classic formulae of Finite Element Method (FEM) which are more effective in numerical calculations than formulae (6-11). Regardless of the applied method the calculated forces are linear combinations of structural displacements and the stiffness properties of the structure. The support elastic forces $\left\{f_{g}\right\}$ better represent the propagation effects on structure than dynamic displacements of the structure as they combine both dynamic and pseudo-static response.

Solving the eigenproblem of the analyzed discrete system leads to eigenmatrix $[\mathrm{W}]$ and natural frequencies $\omega_{1}, \omega_{2}, \ldots, \omega_{n_{s}}$. Introducing normal coordinates $\underline{q}_{1}, \underline{q}_{2}, \ldots$, $\underline{\mathrm{q}}_{\mathrm{s}}$ and applying the modal transformation

$$
\{\mathrm{q}\}=[\mathrm{w}]\{\underline{\mathrm{q}}\}
$$

leads, after some algebra [15], to following formulas for mean square displacements

$$
\sigma_{\mathrm{q}_{k}}^{2} \cong \sum_{\mathrm{i}=1 \mathrm{p}=1}^{\mathrm{n}_{\mathrm{w}} \mathrm{n}_{\mathrm{w}}} \sum_{-\infty} \mathrm{W}_{\mathrm{ki}} \mathrm{W}_{\mathrm{kp}} \int_{-\infty}^{\infty} \mathrm{H}_{\mathrm{i}}(\omega) \mathrm{H}_{\mathrm{p}}^{*}(\omega) \sum_{\mathrm{j}=1 \mathrm{r}=1}^{\mathrm{n}_{\mathrm{g}} \mathrm{n}_{\mathrm{g}}} \sum_{\mathrm{ij}} \mathrm{g}_{\mathrm{pr}} \mathrm{S}_{\mathrm{jr}}(\omega) \mathrm{d} \omega
$$

and forces

$$
\begin{aligned}
& \mathrm{n}_{\mathrm{s}} \mathrm{n}_{\mathrm{s}} \quad \mathrm{n}_{\mathrm{w}} \mathrm{n}_{\mathrm{w}} \quad \infty \quad \mathrm{n}_{\mathrm{g}} \mathrm{n}_{\mathrm{g}}
\end{aligned}
$$

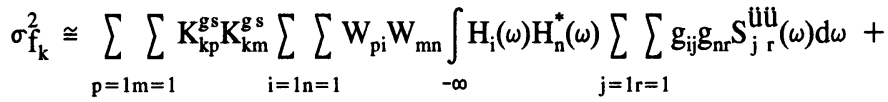

$$
\begin{aligned}
& \begin{array}{lllll}
n_{s} & n_{w} & n_{g} & n_{g} & \infty
\end{array}
\end{aligned}
$$

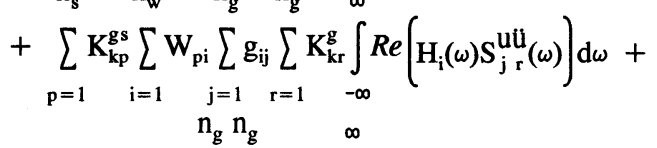

$$
\begin{aligned}
& +\sum_{j=1 \mathbf{r}=1} \mathbf{K}_{\mathbf{k j}}^{\mathrm{g}} \mathbf{K}_{\mathbf{k r}}^{\mathrm{g}} \int_{-\infty}^{\infty} \mathbf{S}_{\mathbf{j} \mathbf{r}}^{\mathrm{uu}}(\omega) \mathrm{d} \omega,
\end{aligned}
$$

where

$\mathrm{W}_{\mathrm{ij}}$ are elements of eigenmatrix $[\mathrm{W}]$,

$H_{i}(\omega)=\left(\omega_{i}^{2}-\omega^{2}+2 i \xi_{i} \omega_{i} \omega\right)^{-1}$ are modal frequency response functions, $i=\sqrt{-1}$

$\mathrm{g}_{\mathrm{ij}}$ are elements of matrix $[\mathrm{g}]=\operatorname{diag}\left[\frac{1}{m_{\mathrm{i}}}\right][\mathrm{W}]^{\mathrm{T}}\left(\left[\mathrm{M}_{\mathrm{ss}}\right]\left[\mathrm{K}_{\mathrm{ss}}\right]^{-1}\left[\mathrm{~K}_{\mathrm{sg}}\right]-\left[\mathrm{M}_{\mathrm{sg}}\right]\right)$,

$S_{\mathrm{jr}}^{\mathrm{uu}}(\omega)=S_{\mathrm{jr}}(\omega)$ are cross spectral densities of excitation accelerations,

$S_{\mathrm{j} \mathrm{r}}^{\mathrm{u}}(\omega)=-S_{\mathrm{jr}}(\omega) / \omega^{2}$ are cross spectral densities displacements-accelerations,

$\mathrm{S}_{\mathrm{j} \mathbf{r}}^{\mathrm{uu}}(\omega)=\mathrm{S}_{\mathrm{jr}}(\omega) / \omega^{4}$ are cross spectral densities of displacements,

$\mathrm{K}_{\mathrm{kr}}^{\mathrm{g}}$ are elements of matrix $\left[\mathrm{K}_{\mathrm{g}}\right]=\left[\mathrm{K}_{\mathrm{gg}}\right]-\left[\mathrm{K}_{\mathrm{gs}}\right]\left[\mathrm{K}_{\mathrm{ss}}\right]^{-1}\left[\mathrm{~K}_{\mathrm{sg}}\right]$,

$\mathrm{K}_{\mathrm{kp}}^{\mathrm{gs}}$ are elements of matrix $\left[\mathrm{K}_{\mathrm{gs}}\right]$, 


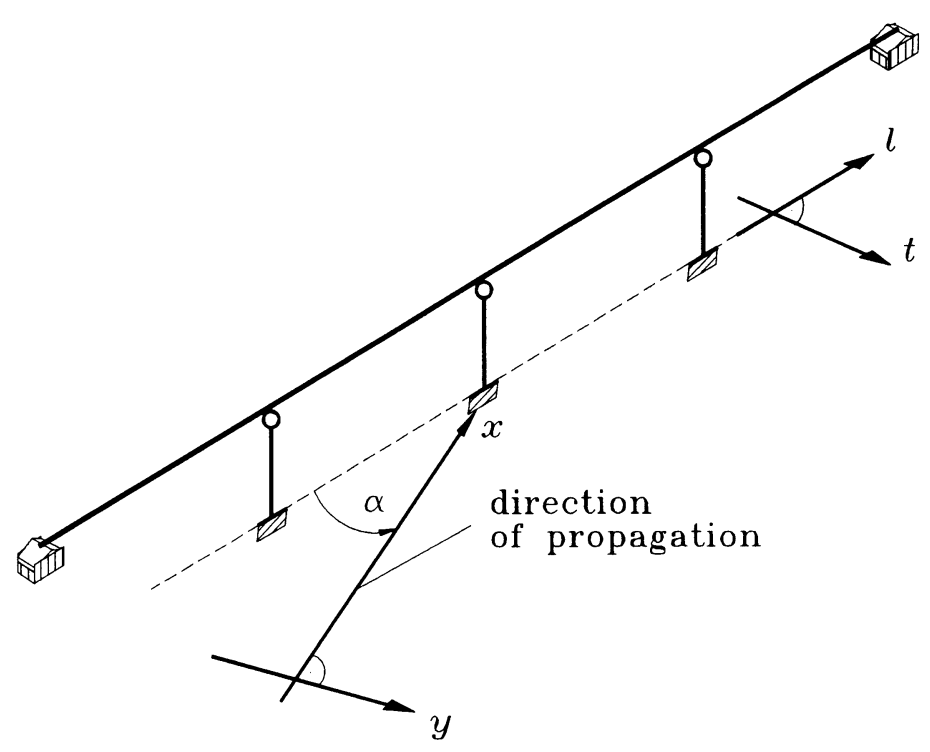

Fig.1 Bridge structure with local $(l-t)$, and principal coordinate system $(x-y)$

\section{Numerical example}

Consider a bridge structure with coordinate system $l, t$ arbitrarily situated with respect to a system of principal axes $x, y$ in which the axis $x$ is directed towards an epicenter and axis $y$ is perpendicular to $x$. Axis $x$ is inclined with angle $\alpha$ to axis $l$ (Fig.1). The horizontal ground motions $u_{x}(t, x, y)$ and $u_{y}(t, x, y)$. They form a random field with uncorrelated $u_{x}$ and $u_{y}$ [13]. Assuming $S_{y y}^{u} u(u)=b^{2} S_{x x}^{u u}(\omega)$ gives:

$$
\left[S_{x y}^{u u}(\omega)\right]=\left[\begin{array}{cc}
S_{x x}^{u u j}(\omega) & 0 \\
0 & S_{y y}^{u u}(\omega)
\end{array}\right]=\left[\begin{array}{cc}
S(\omega) & 0 \\
0 & b^{2} S(\omega)
\end{array}\right]=\left[\begin{array}{ll}
1 & 0 \\
0 & b^{2}
\end{array}\right] S(\omega)
$$

where $S(\omega)$ is the horizontal spectral density of excitation accelerations along propagation direction (axis $x$ ) and $b^{2}=0.7$ here. The transformation of displacements $u_{x}$ and $\mathrm{u}_{\mathrm{y}}$ to $\mathrm{u}_{l}$ and $\mathrm{u}_{t}$ is given through familiar coordinate transformation

$$
\left\{\begin{array}{l}
\mathrm{u}_{l} \\
\mathrm{u}_{t}
\end{array}\right\}=\left[\begin{array}{ll}
\cos (\alpha) & -\sin (\alpha) \\
\sin (\alpha) & \cos (\alpha)
\end{array}\right]\left[\begin{array}{l}
\mathrm{u}_{\mathrm{x}} \\
\mathrm{u}_{\mathrm{y}}
\end{array}\right\}
$$

The analyzed structure is a r/c highway viaduct modeled using FEM as a 3D frame. The data of the bridge were based on an example from Ref.14. The structure can vibrate 


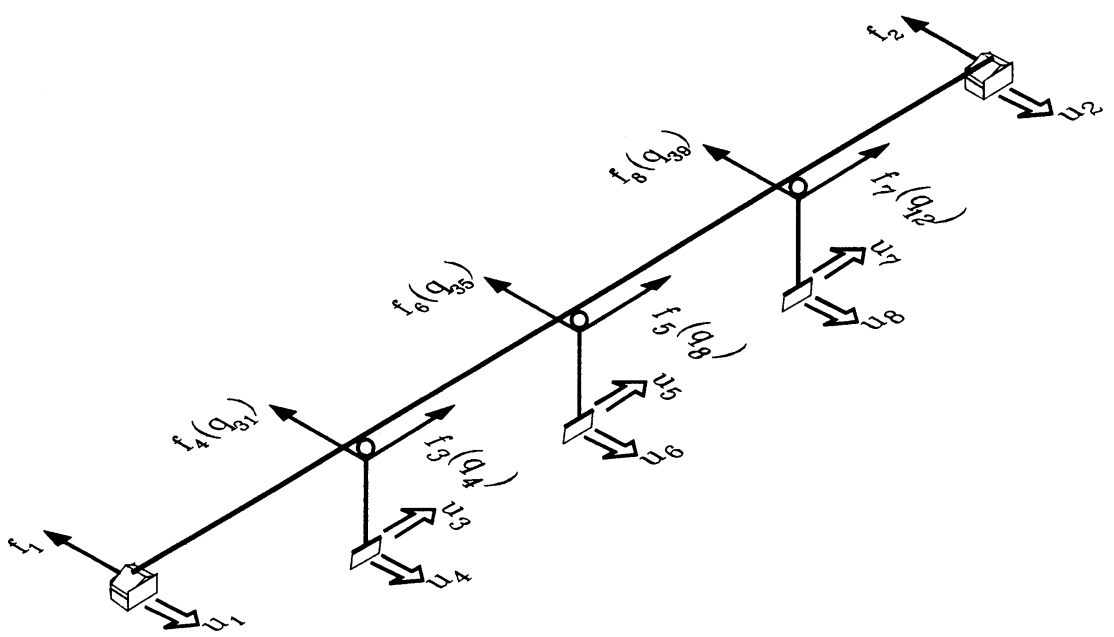

Fig.2 Excitations (u), main response coordinates (q), and shear forces (f)

in horizontal and vertical directions in vertical plane (longitudinal and vertical directions) and out of vertical plane (transversal direction). The supports of the structure have eight horizontal directions of possible excitations $\left(u_{1} \div u_{8}\right.$ in Fig.2). In addition to these eight excitation directions Fig.2 presents also selected FEM displacement coordinates and shear forces of vector $\left\{f_{g}\right\}$. Applying transformation formula (16) to all excitation directions and using eq.15 gives matrix of acceleration cross spectra which is required in eqs. 13 and 14 :

$$
\left[S_{\mathrm{j} \mathrm{r}}^{\mathrm{uu}}(\omega)\right]=\gamma_{\mathrm{jr}}[\mathrm{D}]\left[\begin{array}{cc}
1 & 0 \\
0 & \mathrm{~b}^{2}
\end{array}\right][\mathrm{D}]^{\mathrm{T}} \mathrm{S}(\omega)
$$

where [D] is an extended transformation matrix, $\gamma_{\mathrm{jr}}$ is a complex coherency function of signals at directions " $\mathrm{j}$ " and " $\mathrm{r}$ " and $\mathrm{S}(\omega)$ is a real, point spectral density [15-17]:

$$
S(\omega)=\frac{\omega_{g}^{4}+4 \xi_{g}^{2} \omega_{g}^{2} \omega^{2}}{\left(\omega_{g}^{2}-\omega^{2}\right)^{2}+4 \xi_{g}^{2} \omega_{g}^{2} \omega^{2}} \frac{\omega^{4}}{\left(\omega_{1}^{2}-\omega^{2}\right)^{2}+4 \xi_{1}^{2} \omega_{1}^{2} \omega^{2}} S_{0},
$$

where $S_{0}$ is an intensity factor and the remaining constants are as follows: $\omega_{g}=4 \pi$, $\xi_{\mathrm{g}}=0.6, \omega_{1}=1.636, \xi_{1}=0.619$. The coherency function may be written in exponential form

$$
\gamma_{j r}\left(\omega, d_{j r}^{x}, d_{j r}^{y}\right)=\left|\gamma_{j r}\left(\omega, d_{j r}^{x}, d_{j r}^{y}\right)\right| \exp \left(i \omega d_{j r}^{x} / v_{g}\right) \text {. }
$$


The exponent in formula 19 describes wave propagation effects along axis $x$. It depends on apparent wave velocity $\mathrm{v}_{\mathrm{g}}$ and projection of distance between points " $\mathrm{j}$ " and " $\mathrm{r}$ " on axis $x \mathrm{~d}_{\mathrm{jr}}^{\mathrm{x}}\left(\mathrm{d}_{\mathrm{jr}}^{\mathrm{y}}\right.$ is respective projection on axis $y$ ). The modulus of coherency in formula 19 can be found in the Literature following field measurements of seismic ground motion. In this study a formula given by Hao [8] will be applied:

$$
\left|\gamma_{\mathrm{jr}}\left(\omega, \mathrm{d}_{\mathrm{jr}}^{\mathrm{x}}, \mathrm{d}_{\mathrm{jr}}^{\mathrm{y}}\right)\right|=\exp \left(-\beta_{1} \mathrm{~d}_{\mathrm{jr}}^{\mathrm{x}}-\beta_{2} \mathrm{~d}_{\mathrm{jr}}^{\mathrm{y}}\right) \exp \left(-\left(\alpha_{1}(\omega) \sqrt{\mathrm{d}_{\mathrm{jr}}^{\mathrm{x}}}+\alpha_{2}(\omega) \sqrt{\mathrm{dy}_{\mathrm{jr}}}\right)\left(\frac{\omega}{2 \pi}\right)^{2}\right),
$$

where

$$
\begin{aligned}
& \alpha_{1}(\omega)=\frac{2 \pi a_{1}}{\omega}+\frac{a_{2} \omega}{2 \pi}+a_{3} \text { for } 0.314 \leq \omega \leq 62.83 . \\
& \alpha_{2}(\omega)=\frac{2 \pi a_{4}}{\omega}+\frac{a_{5} \omega}{2 \pi}+a_{6}
\end{aligned}
$$

For $\omega \geq 62.83 \alpha_{1}(\omega)=\alpha_{1}(62.83)=$ const and $\alpha_{2}(\omega)=\alpha_{2}(62.83)=$ const. The constants $\beta_{1}, \beta_{2}$ and $a_{1} \div a_{6}$ have been taken from event 45 of SMART 1 , [8].

Three main parameters affect the response of structure in this case: apparent wave velocity $v_{g}$, the angle of propagation $\alpha$, and the loss of coherency $\left|\gamma_{j r}\right|$. The effect of the first two of them on structural response is analyzed in Fig. 3 where the root mean square displacements $\sigma_{y_{35}}$ (Fig.3a) and $\sigma_{f_{6}}$ (Fig.3b) are presented as the functions of apparent wave velocity and angle $\alpha$. The presented rms displacements and forces are normalized with respect to uniform excitations. It can be seen from this figure that the incoherent motion of supports reduces the dynamic displacements of the structure, but the force response can be either decreased or increased depending mostly on the propagation velocity. A substantial decrease can be observed for $\mathrm{v}_{\mathrm{g}} \cong 100 \div 200 \mathrm{~m} / \mathrm{s}$. For very low propagation velocity (less then about $50 \mathrm{~m} / \mathrm{s}$ ) the incoherent excitations make the increase of force response mostly due to increasing contribution of pseudo-static motion. The effect of angle $\alpha$ on the response is also substantial. For high velocity $v_{g}$ it reflects simply the projections of excitations on the structural coordinate system $(l-t)$. For lower propagation velocity the response is very sensitive to changes of angle $\alpha$.

\section{Final remarks and conclusions}

3D random vibrations of a bridge structure under kinematic wave excitations are considered. Both dynamic displacement response and force response are analyzed. The displacement response is reduced compare to coherent excitations while the force response can be either reduced or amplified depending on propagation velocity and angle. Pseudo-static motion contributes substantially in structural response for low 

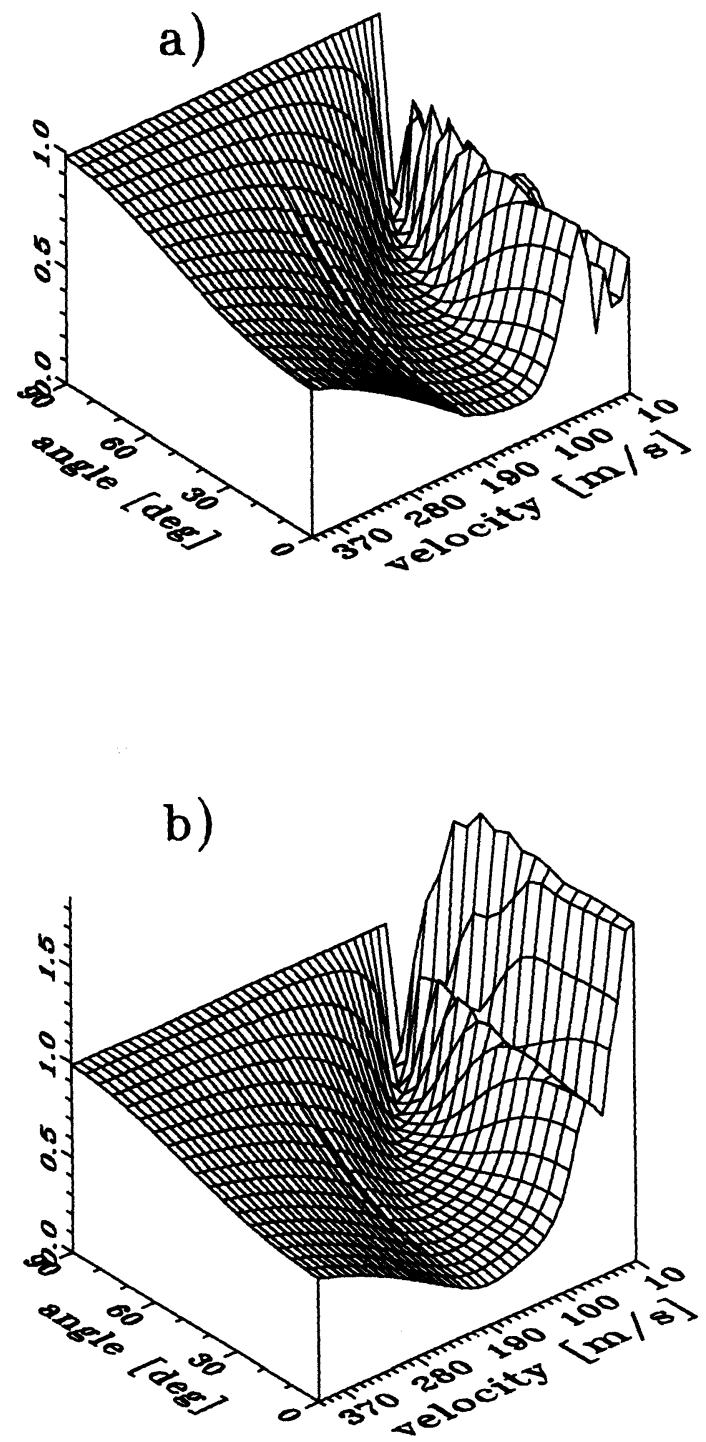

Fig.3 Rms displacements $q_{35}$ (a) and shear force $f_{6}$ (b) vs. propagation angle and velocity, normalized with respect to uniform excitations 
propagation velocity $\left(\mathrm{v}_{\mathrm{g}}<50 \mathrm{~m} / \mathrm{s}\right)$.

\section{Acknowledgements}

A partial support of Committee of Scientific Research (Grant number PB $0373 / \mathrm{P} 4 / 94 / 06)$ is gratefully acknowledged.

\section{References}

1. Loh C.-H., Penzien J. and Tsai Y.B., Engineering analysis of SMART 1 array accelerograms, Earthquake Engineering and Structural Dynamics, 10, 1982, 575-591.

2. Abrahamson N.A. and Bolt B.A., The spatial variation of the phasing of seismic strong ground motion, Bulletin of the Seismological Society of America, 75, 1985, 1247-1264.

3. Der Kiureghian A. and Neuenhofer A., A response spectrum method for multiplesupport seismic excitations, Report No. UCB/EERC 91/08, 1991, Earthquake Engineering Research Center, University of California, Berkeley.

4. Zembaty Z. and Krenk S. Spatial seismic excitations and response spectra, Journal of Engineering Mechanics, ASCE, 119, 1993, 2449-2460.

5. Harichandran R.S. and Wang W., Response of simple beam to spatially varying earthquake excitation, Journal of Engineering Mechanics , ASCE, 114, 1988, 15261541.

6. Harichandran R.S. and Wang W., Response of indeterminate two-span beam to spatially varying seismic excitation, Earthquake Engineering and Structural Dynamics, 19, 1990, 173-187.

7. Zerva A., Effect of spatial variability and propagation of seismic ground motions on the response of multiply supported structures, Probabilistic Engineering Mechanics, 6, 1991, 212-221.

8. Hao H., Effects of spatial variation of ground motion on large multiply-supported structures, Report No. EERC 89-06, 1989, Earthquake Engineering Research Center, University of California, Berkeley, CA .

9. Novak M., Spatial correlation effects in random vibration of structures, Structural Dynamics, Proceedings of EURODYN '90, Krätzig et al. (eds), Balkema, Rotterdam, 1990, vol.2, 631-636.

10.Leger P., Idè I.M. and Paultre P., Multiple-support seismic analysis of large structures, Computer and Structures, 36, 1990, 1153-1158.

11.Heredia Zavoni E. and Vanmarcke E.H., Seismic random-vibration analysis of multisupport-structural systems, Journal of Engineering Mechanics , ASCE, 120, 1994, 1107-1128.

12.Zembaty Z., Vibrations of a bridge structure under kinematic wave excitations ( $a$ paper in preparation).

13.Penzien J. and Watabe M., Characteristics of 3-dimensional earthquake ground motions, Earthquake Engineering and Structural Dynamics, 3, 1975, 365-373.

14.Lai P., Seismic response of a 4-span bridge system subjected to multiple-support ground excitation, Proceedings of 4th Canadian Conference on Earthquake Engineering, University of British Columbia, Vancouver, Canada, 1983, 561-570.

15.Kanai K., Semi-empirical formula for the seismic characteristic of the ground, Bulletin of Earthquake Research Institute, Tokyo, vol.35, 1957, 309-325.

16.Tajimi H., A statistical method of determining the maximum response of a building structure during an earthquake, Proceedings of 2nd World Conference on Earthquake Engineering, Tokyo, 1960, vol.2, 781-798.

17.Ruiz. P. and Penzien J., Probabilistic study of the behavior of structures during earthquakes, Report No. EERC 69-03, Earthquake Engineering Research Center, University of California, Berkeley, CA, 1969. 